\title{
Botulismo em bovinos de corte e leite alimentados com cama de frango ${ }^{1}$
}

\author{
Iveraldo S. Dutra ${ }^{2 *}$, Jürgen Döbereiner ${ }^{3}$ e Aires M. Souza ${ }^{4}$
}

\begin{abstract}
Dutra I.S., Döbereiner J. \& Souza A.M. 2005. [Botulism in beef and dairy cattle fed with poultry litter.] Botulismo em bovinos alimentados com cama de frango. Pesquisa Veterinária Brasileira 25(2):115-119. Depto Apoio, Produção e Saúde Animal, Curso de Medicina Veterinária, Universidade Estadual Paulista (Unesp), Rua Clóvis Pestana 793, Araçatuba, SP 16065-080, Brazil. Email: isdutra@fmva.unesp.br

Outbreaks of botulism caused by type $C$ and $D$ of the botulinum toxin are frequent in Brazil, and are associated with bone chewing and ingestion of contaminated food and water. This paper reports the epidemiological, clinical, pathological and laboratorial aspects of 7 outbreaks of botulism in beef and dairy cattle fed with poultry litter, which occurred in the states of São Paulo and Minas Gerais, 1989-2000. Five outbreaks occurred in beef cattle herds, raised in confinement or under pasture conditions and supplemented with poultry litter, and 2 outbreaks occurred in dairy farms. From o total of 1,535 cattle supplemented regularily with poultry litter 455 animals (29.64\%) died within 2 to 4 weeks. Morbidity and mortality varied from 3.47 to $100 \%$ in the 7 outbreaks. In one of the farms the lethality was $60.52 \%$, and in others more than $88.43 \%$, reaching $100 \%$ in three farms. Clinical signs were progressive paralysis, difficulties in moving, decubitus, normal alertness, decreased muscular tonus of tongue and tail, sialorrhoe and dyspnoe. At post-mortem examination of 30 cattle no noteable changes were observed. Spores of Clostridium botulinum were found in poultry litter samples collected on 7 farms. In liver, ruminal and intestinal fluid samples from 30 necropsied cattle botulinum toxin of type C (5) and $\mathrm{D}(9)$ or of the $\mathrm{CD}$ complex (1) were found in at least one of the samples collected from 15 animals, which confirms the clincial, pathological and epidemiological diagnosis of botulism.
\end{abstract}

INDEX TERMS: Botulism, cattle, poultry litter.

RESUMO.- Surtos de botulismo causados pelos tipos C e D da toxina botulínica são freqüentes no país, estando originalmente associados à osteofagia e à ingestão de alimentos e água contaminados. No presente trabalho são descritos os aspectos epidemiológicos, clínico-patológicos e laboratoriais de sete surtos da intoxicação em bovinos de corte e leite alimentados com cama de frango, ocorridos nos estados de São Paulo e Minas Gerais entre 1989 e 2000. Cinco surtos ocorreram em rebanhos de corte confinados ou criados extensivamente e suplementados

\footnotetext{
${ }^{1}$ Recebido em 18 de julho de 2004.

Aceito para publicação em 15 de dezembro de 2004.

2 Depto Apoio, Produção e Saúde Animal, Curso de Medicina Veterinária, Universidade Estadual Paulista (Unesp), Rua Clóvis Pestana 793, Araçatuba, SP 16050-680. *Autor para correspondência. E-mail: isdutra@fmva.unesp.br

${ }^{3}$ Projeto Sanidade Animal Embrapa/UFRRJ, Seropédica, RJ 23890-000.

${ }^{4}$ Depto Medicina Veterinária Preventiva, Universidade Federal de Goiás, Goiânia, GO.
}

com o subproduto, e dois em propriedades leiteiras. De um total de 1.535 animais alimentados regularmente com a cama de frango, $455(29,64 \%)$ morreram em um período que variou de 2 a 4 semanas. A morbidade nos sete surtos estudados variou de 3,47 a $100 \%$, da mesma forma que a mortalidade. Em uma das propriedades a letalidade foi de $60,52 \%$, e em todos os outros surtos ela foi acima de $88,43 \%$; em três propriedades o coeficiente foi de $100 \%$. Os sinais clínicos de paralisia progressiva, dificuldade na locomoção, decúbito e estado mental aparentemente normal, diminuição do tônus da musculatura da língua e cauda, sialorréia e dificuldade respiratória caracterizaram o quadro clínico. À necropsia de 30 animais não foi observada qualquer alteração macroscópica digna de nota. A presença de esporos de Clostridium botulinum foi detectada em amostras de cama de frango colhidas nas sete propriedades. Nas amostras de fígado, líquido ruminal e intestinal, provenientes dos 30 animais necropsiados, foi possível detectar toxinas botulínicas tipos $C$ (5) ou D (9), ou classificada como pertencente ao complexo CD (1), em pelos menos um dos materiais provenientes de 15 animais, 
confirmando assim o diagnóstico clínico-patológico e epidemiológico de botulismo.

TERMOS DE INDEXAÇÃO: Botulismo, bovinos, cama de frango.

\section{INTRODUÇÃO}

A intoxicação botulínica é uma importante causa de mortalidade bovina na pecuária extensiva, estando geralmente associada à osteofagia (Tokarnia et al. 1970, Döbereiner et al. 1992, Dutra 2001) ou à intoxicação por veiculação hídrica (Dutra et al. 2001). A ausência da prática de se destruir cadáveres nas propriedades rurais e a ocorrência de mortalidade pelo botulismo contribuiu para a intensificação da contaminação ambiental pelos esporos de Clostridium botulinum (Souza \& Langenegger 1987, Ribas et al. 1994). Em decorrência ou paralelo a essa condição epidemiológica, surtos associados ao uso de alimentos contaminados também foram registrados (Dutra 2001) com sérios prejuízos aos produtores.

O uso da cama de frango na alimentação de bovinos, ou mesmo na adubação de pastagem, foi uma prática zootécnica muito difundida e incentivada no país, até a sua proibição em 2001 pela Instrução Normativa no.15 do Ministério da Agricultura, Pecuária e Abastecimento, como uma das medidas preventivas para se evitar no país os riscos potenciais da encefalopatia espongiforme bovina (MAPA 2001). No entanto, as inexpressivas ações de educação sanitária e as dificuldades operacionais na fiscalização pelos órgãos oficiais não asseguram a sua exclusão pelos produtores.

Um dos riscos sanitários adicionais, decorrentes do seu uso na alimentação animal, é o da intoxicação botulínica pelos tipos C ou $\mathrm{D}$, que pode estar associada à ingestão da cama de frango pelos animais (McLoughlin et al. 1988, Kriek \& Odendaal 1994) ou ao seu emprego na adubação de pastagem (Hogg et al. 1990), possibilitando da mesma forma o seu acesso e ingestão. 0 objetivo do presente artigo é o de descrever aspectos epidemiológicos, clínico-patológicos e laboratoriais de surtos de botulismo em rebanhos bovinos de corte e leite alimentados com cama de frango e registrados antes da proibição do seu uso na alimentação de ruminantes em 2001.

\section{MATERIAL E MÉTODOS}

São descritos e analisados os aspectos epidemiológicos, clínicopatológicos e resultados laboratoriais relacionados a sete surtos de botulismo em bovinos de corte e leite, ocorridos no período de 1989 a 2000 nos estados de São Paulo e Minas Gerais. Por ocasião da ocorrência do problema foram realizadas visitas às propriedades rurais para a realização de levantamento epidemiológico, exame clínico dos animais enfermos, realização de necropsias e colheita de material para análise laboratorial.

Aspectos epidemiológicos. O levantamento epidemiológico realizado nas propriedades foi baseado em informações obtidas diretamente do proprietário, administrador ou pessoal de lida do gado, e averiguadas in loco por ocasião da visita à propriedade. Os coeficientes de morbidade, mortalidade e letalidade foram calculados utilizando-se os preceitos considerados por Thrusfield (2004), com base nos dados relacionados estritamente ao problema em evidência.

Exame clínico dos animais. O exame clínico dos animais constou da avaliação das funções vitais (temperatura e frequiências cardíaca, respiratória e movimentos ruminais) e coloração das mucosas. $O$ exame neurológico consistiu na observação e avaliação da postura, do estado mental, da avaliação da acuidade visual e auditiva, da presença de reflexo pupilar, da verificação do tônus da musculatura dos membros, da cauda e da língua e ainda da sensibilidade cutânea, conforme os preceitos estabelecidos por Stöber (1988).

As informações sobre a evolução clínica foram obtidas por ocasião da visita à propriedade e através de contato posterior, e constou do registro do período aproximado desde o aparecimento dos primeiros sinais clínicos observados até o momento da morte do animal, ou ainda da sua eventual recuperação. De acordo com este período, a evolução clínica foi classificada como superaguda (evolução com morte dentro de $24 \mathrm{~h}$ ), aguda (24-48h), subaguda (48h a 7 dias) e crônica (evolução acima de 7 dias), em conformidade com a divisão arbitrária estabelecida por Theiler \& Robinson (1927).

Necropsia e colheita de material. Foram necropsiados animais mortos em período não superior a 3 horas ou ainda sacrificados em estágio terminal da enfermidade, para a verificação de alterações macroscópicas e colheita de fragmentos do fígado (aprox.100g) e líquido ruminal $(20 \mathrm{~mL})$ e intestinal $(20 \mathrm{~mL})$ para a tentativa de detecção de toxina botulínica. Os materiais colhidos foram mantidos sob refrigeração ou congelados (-20C) até o exame laboratorial.

Deteç̧ão de toxina botulínica. A tentativa de deteç̧ão de toxina botulínica nos espécimes colhidos dos animais foi realizada conforme descrito por Smith (1977). As amostras de fígado foram trituradas em gral estéril, com tampão fosfato gelatina, até a obtenção de suspensão homogênea. Desta forma, foram mantidas sob refrigeração por um período de 12-24 horas para a eluição da toxina eventualmente presente no tecido hepático. Após este período o sobrenadante foi centrifugado a $12.000 x g$ por 20 minutos, filtrado em Millipore $(0,22 \mu \mathrm{m})$ e avaliado quanto à sua toxicidade no bioensaio e neutralização em camundongo. As amostras de líquido ruminal e intestinal foram diluídas 1:2 em tampão fosfato gelatina, centrifugadas, filtradas e da mesma forma avaliadas na prova biológica. Amostras de cama de frango quando avaliadas para a presença de toxina botulínica foram processadas da mesma forma que as de líquido ruminal e intestinal.

Esporos de Clostridium botulinum na cama de frango. Para a tentativa de detecção indireta de esporos de $C$. botulinum na cama de frango foram colhidas amostras aleatórias do subproduto armazenado ou presente nos comedouros dos animais. Alíquotas do alimento suspeito foram diluídas em tampão fosfato gelatina e inoculadas em meio de cultura de carne cozida, conforme metodologia preconizada por Smith (1977). Após tratamento térmico de $80^{\circ} \mathrm{C}$ por 60 minutos, o meio de cultura foi incubado por cinco dias a $35^{\circ} \mathrm{C}$. Após este período o sobrenadante foi centrifugado a $12.000 x$ e filtrado em Millipore $(0,22 \mathrm{~mm})$, para a realização do bioensaio e neutralização em camundongo.

Bioensaio e neutralização em camundongo. Foram inoculados $0,5 \mathrm{~mL}$ do filtrado pela via intraperitoneal em camundongo da raça Swiss, linhagem Webster, de ambos os sexos, com peso entre 18 e $22 \mathrm{~g}$, e em duplicata, de acordo com as recomendações de Smith (1977), para a tentativa preliminar de detecção de toxina botulínica nos espécimes clínicos e no sobrenadante do meio de cultura. Alíquotas de $0,5 \mathrm{~mL}$ dos mesmos materiais, aquecidas previamente a $100^{\circ} \mathrm{C}$ por 10 minutos, foram inoculadas paralelamente para a evidenciação da inativação da toxina botulínica eventualmente presente. Os camundongos foram observados por um período de 96h para a verificação de sintomatologia e morte. Materiais considerados positivos foram submetidos à neutralização em camundongo, conforme os procedimentos descritos por Dowell \& Hawkins (1974). 
As antitoxinas utilizadas foram obtidas do "Staatens Serum Institut", Copenhagen, Dinamarca, ou do "Center for Disease Control", Atlanta, Georgia, Estados Unidos.

\section{RESULTADOS E DISCUSSÃO}

A ocorrência em larga escala no país de surtos de botulismo nas duas últimas décadas causou sérios prejuízos econômicos aos produtores de carne e leite. Associado inicialmente à osteofagia, manifestada pelos bovinos mantidos em áreas deficientes em fósforo, ou à ingestão de água contaminada, o botulismo ocasionado por alimentos também ocorreu em diversas regiões do país (Dutra 2001).

No presente estudo são registrados sete surtos de mortalidade bovina em propriedades rurais localizadas nos estados de São Paulo e Minas Gerais (Quadro 1), em que a cama de frango era usada regularmente na alimentação dos animais. Cinco surtos ocorreram em rebanhos de corte confinados ou criados extensivamente e suplementados com o subproduto, e dois em propriedades leiteiras.

A morbidade variou de $3,47 \%$ a $100 \%$, da mesma forma que a mortalidade. Com exceção do surto ocorrido em Passos, MG, em que a letalidade foi de $60,52 \%$, em todos os outros ela esteve acima de $88,43 \%$, sendo que em três propriedades atingiu o coeficiente de $100 \%$. De um total de 1535 animais que estavam recebendo na dieta a cama de frango nas sete propriedades rurais, $455(29,64 \%)$ morreram em um período que variou entre 2 e 4 semanas. Segundo Kriek \& Odendaal (1994), a alta letalidade é uma característica epidemiológica importante a ser considerada nos surtos de botulismo e está relacionada à sensibilidade dos bovinos e à quantidade de toxina eventualmente presente no alimento contaminado e ingerido. Em cinco propriedades foi possível verificar a presença de restos de carcaças de aves (Fig.1) no interior da cama de frango ainda armazenada, embora tenha sido relatada pelos responsáveis a prática de limpeza prévia do subproduto.

Pelo histórico, nenhum dos rebanhos havia sido vacinado contra o botulismo, o que muito provavelmente contribuiu para a elevada morbidade e mortalidade registradas. Embora seja desconhecida a eficácia da vacina anti-botulínica em bovinos alimentados com a cama de frango, o seu uso profilático na pecuária extensiva resultou em redução significativa na probabilidade da intoxicação em situação de alto risco (Dutra et al. 1996).

Nos dois surtos que ocorreram em rebanhos leiteiros foi relatada a diminuição drástica na produção de leite nos dias imediatamente anteriores ao aparecimento dos primeiros sinais

Quadro 1. Dados epidemiológicos dos surtos de botulismo em bovinos de corte e leite, alimentados com cama de frango, nos estados de São Paulo e Minas Gerais, registrados no período de 1989 a 2000

\begin{tabular}{|c|c|c|c|c|c|c|c|c|c|c|}
\hline Surto & Município & Estado & Ano & $\begin{array}{c}\text { Tipo } \\
\text { exploração }\end{array}$ & $\begin{array}{l}\text { Animais } \\
\text { risco }\end{array}$ & $\begin{array}{l}\text { Animais } \\
\text { doentes }\end{array}$ & $\begin{array}{l}\text { Animais } \\
\text { mortos }\end{array}$ & $\begin{array}{c}\text { Morbidade } \\
(\%)\end{array}$ & $\begin{array}{c}\text { Mortalidade } \\
\%)\end{array}$ & $\begin{array}{c}\text { Letalidade } \\
(\%)\end{array}$ \\
\hline 1 & Matias Barbosa & MG & 1989 & Corte & 68 & 68 & 68 & 100 & 100 & 100 \\
\hline 2 & Descalvado & SP & 1990 & Corte & 230 & 8 & 8 & 3,43 & 3,47 & 100 \\
\hline 3 & Pedregulho & SP & 1991 & Corte & 40 & 19 & 17 & 47,5 & 42,5 & 89,47 \\
\hline 4 & Araraquara & SP & 1991 & Corte & 370 & 71 & 63 & 19,18 & 17,0 & 88,73 \\
\hline 5 & S. J. Rio Preto & SP & 1995 & Leite & 35 & 35 & 34 & 100 & 97,14 & 97,14 \\
\hline 6 & Santa Vitória & MG & 2000 & Corte & 670 & 242 & 242 & 36,11 & 36,11 & 100 \\
\hline 7 & Passos & MG & 2000 & Leite & 122 & 38 & 23 & 31,14 & 18,85 & 60,52 \\
\hline
\end{tabular}

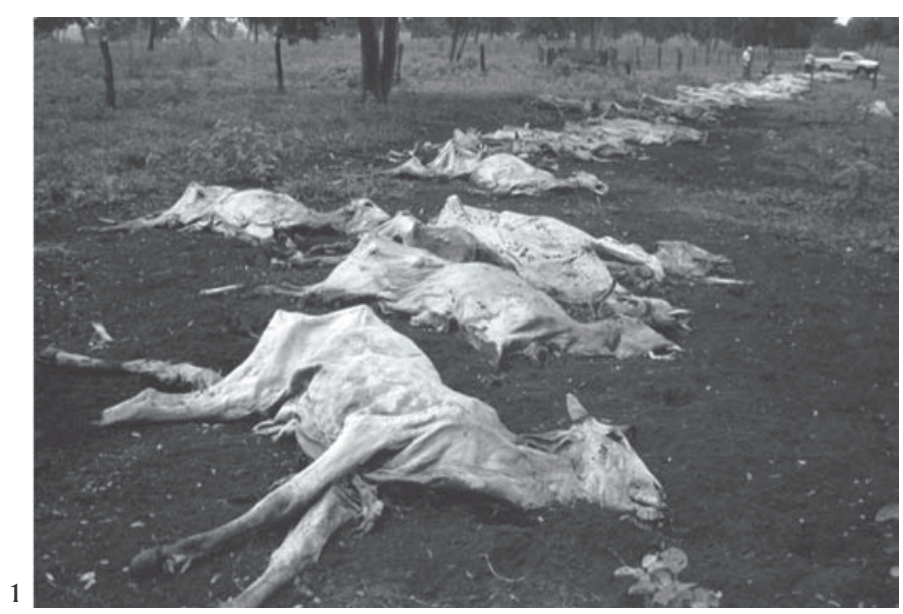

Fig. 1. Cadáveres de bovinos de corte acometidos pela intoxicação botulínica, em face da ingestão de cama de frango contaminada (Santa Vitória, MG).

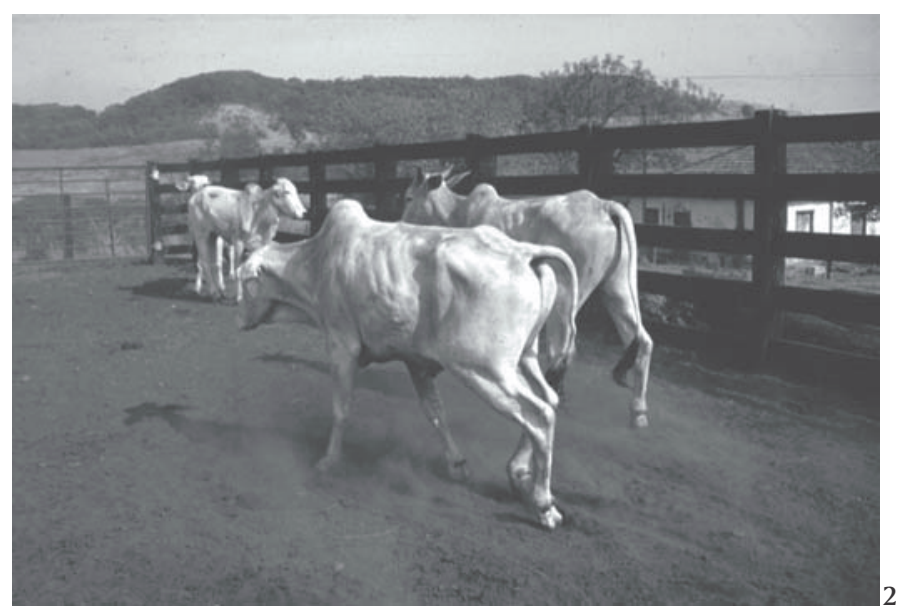

Fig. 2. Bovino com dificuldade na locomoção, acentuadamente nos membros posteriores, em decorrência da intoxicação botulínica pela ingestão de cama de frango. Esta manifestação, após o animal ter sido submetido a esforço físico, foi observada em animais com intoxicação crônica, alguns dos quais sobreviveram (Araraquara, SP). 

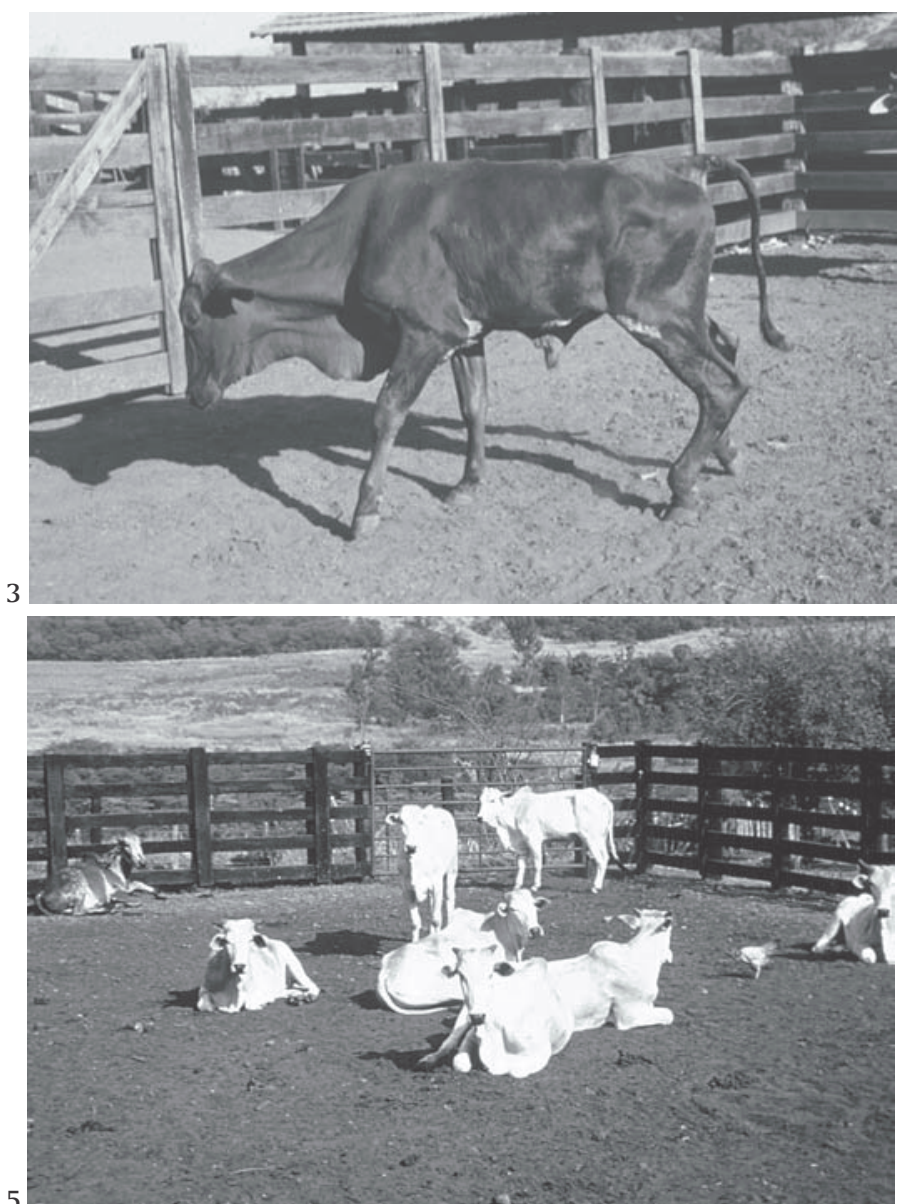

Fig. 3. Dificuldade na locomoção e poliflexão dos membros em bovino com intoxicação crônica pela ingestão de cama de frango e que sobreviveu à intoxicação botulínica (Araraquara, SP).

Fig. 5. Animais com manifestações clínicas de diferentes intensidades da intoxicação botulínica, em decúbito e com estado mental aparentemente normal (Araraquara, SP).

clínicos nos animais. Este evento também foi descrito por Hogg et al. (1990) que registraram ainda a ocorrência de inapetência no rebanho no período imediatamente anterior à ocorrência de um surto.

Pelo exame clínico realizado em 54 animais nos surtos estudados foi possível caracterizar os sinais mais representativos como a dificuldade na locomoção (Fig.2), acentuadamente dos membros pélvicos (Fig.3), poliflexão dos membros (Fig.4) e emboletamento (Fig.5), decúbito e estado mental aparentemente normal (Fig.6) com paralisia progressiva, diminuição do tônus da musculatura da língua e cauda, sialorréia nos casos superagudos (Fig.7), dificuldade respiratória, com inspiração bifásica, bradicardia e diminuição do movimento ruminal. Embora esses sinais não estavam necessariamente bem definidos em todos os animais examinados no momento do exame clínico, eles representam claramente o que ocorre na intoxicação botulínica. De acordo com Stöber (1984), o quadro de paralisia flácida progressiva, aliado ao estado mental aparentemente nor-
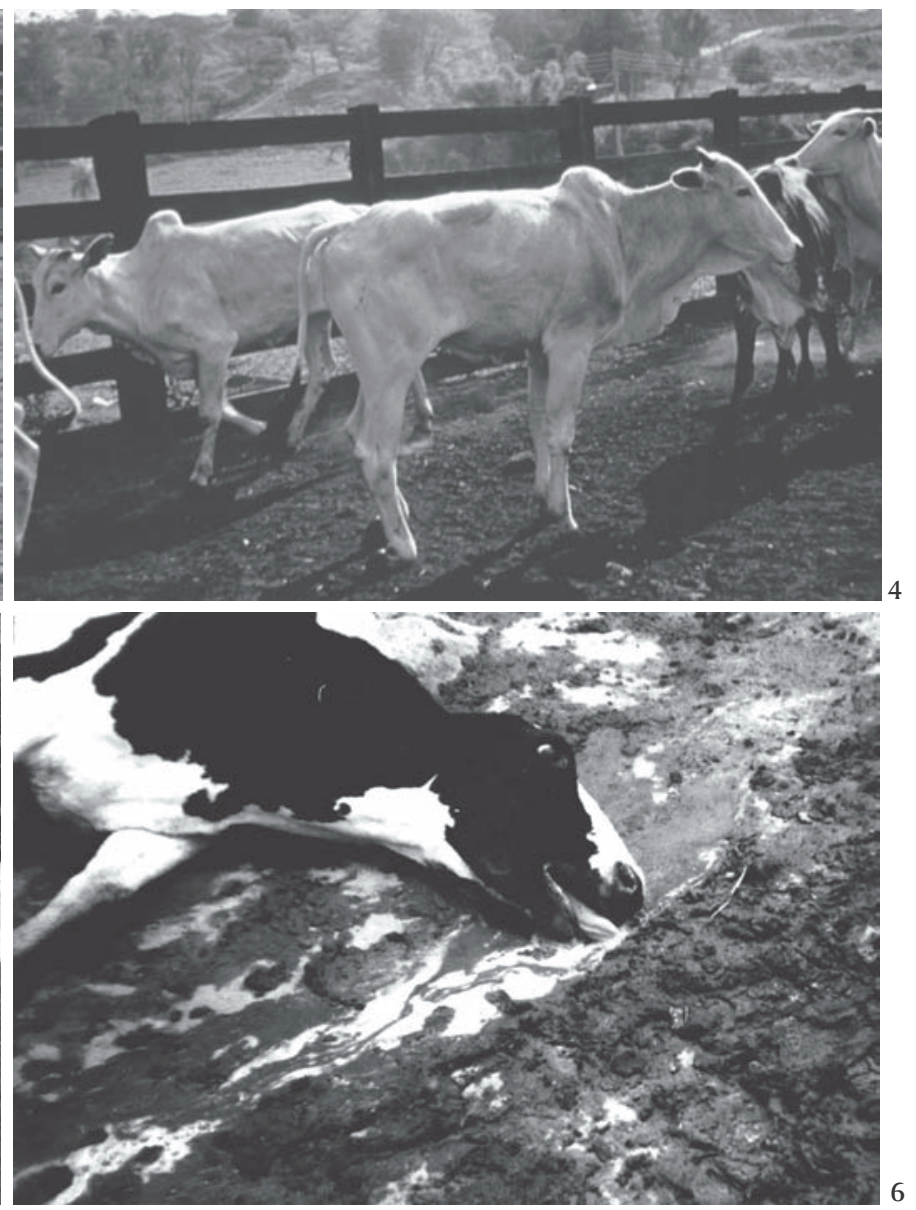

Fig. 4. Bovino, afetado pelo botulismo em face da ingestão de cama de frango contaminada, com dificuldade na locomoção e apresentando emboletamento das extremidades dos membros posteriores (Araraquara, SP).

Fig. 6. Vaca mestiça com dificuldade respiratória e sialorréia em decorrência da intoxicação botulínica superaguda pela cama de frango (São José do Rio Preto, SP).

mal e respiração bifásica na inspiração é característico do botulismo e auxilia sobremaneira no estabelecimento do diagnóstico clínico diferencial de outras enfermidades do sistema nervoso dos bovinos. Por outro lado, a intensidade da manifestação clínica do botulismo está condicionada à quantidade de toxina ingerida, da mesma forma que a sua evolução clínica (Kriek \& Odendaal 1994).

Dos 54 animais examinados, cinco apresentaram evolução clínica superaguda, 24 aguda, 12 subaguda e 13 crônica, revelando as diferentes intensidades da manifestação e evolução clínica, geralmente decorrente da quantidade de toxina ingerida pelos animais. Os 26 animais que sobreviveram, em quatro dos sete surtos, manifestaram o quadro crônico da enfermidade caracterizado por distúrbios moderados na locomoção, visualizados principalmente quando eram submetidos ao esforço físico.

Nas necropsias realizadas em 30 animais para a colheita de material, não foram encontradas alterações dignas de nota. 
A presença de esporos de Clostridium botulinum foi constatada em uma das amostras de cama de frango colhidas nos sete surtos. Das 24 amostras examinadas, 18 foram positivas para os tipos C (6), D (10) ou classificadas como pertencentes ao complexo $\mathrm{CD}(2)$. Estes resultados revelaram apenas a contaminação da cama de frango pelo microrganismo e não têm validade diagnóstica, uma vez que isto pode ocorrer naturalmente. No entanto, a contaminação da cama de frango pelos esporos da bactéria é o indicador primário da existência de condição prévia potencial para a ocorrência do botulismo. Não foi constatada a presença de toxina botulínica em qualquer das 12 amostras de cama de frango examinadas e oriundas das propriedades 3 a 7 .

Das amostras de fígado, líquido ruminal e intestinal, provenientes de 30 bovinos com diferentes evoluções clínicas, em 15 animais foi possível detectar toxina botulínica em um dos espécimes examinados. Assim, foi detectada toxina botulínica em dois animais com evolução clínica superaguda, seis com evolução aguda, quatro subaguda e três com evolução crônica. Dos 15 animais positivos, 9 foram intoxicados pela toxina tipo $\mathrm{D}, 5$ pelo tipo C e 1 classificado no complexo CD. Nos dois primeiros surtos registrados, ocorridos em Matias Barbosa, MG, e Descalvado, SP, não foi possível detectar toxina botulínica em qualquer um dos oito animais examinados. Nos outros surtos, em pelo menos um dos animais necropsiados foi possível realizar o diagnóstico laboratorial comprobatório.

Vale ressaltar que, hipoteticamente, a probabilidade de se comprovar laboratorialmente a presença de toxina botulínica em espécimes colhidos de bovinos aumentaria em função da quantidade de animais examinados em um surto. No entanto, foram examinados materiais provenientes de oito animais dos Surtos 1 e 2, sem que houvesse qualquer resultado positivo no bioensaio. Dutra (2001) determinou a sensibilidade do bioensaio em camundongo em $43,1 \%$, quando são examinadas amostras de fígado, líquido ruminal e intestinal de bovinos com sintomatologia clínica de botulismo. Assim, o fato de nos dois primeiros surtos não terem sido detectadas toxina botulínica em qualquer dos animais examinados não exclui o diagnóstico da enfermidade. Esta é, aliás, uma característica marcante na intoxicação botulínica em bovinos, em que nem sempre é possível se estabelecer o diagnóstico comprobatório da presença da toxina.

A proibição oficial do uso da cama de frango na alimentação de ruminantes no país não exclui o seu emprego na adubação de pastagem. Por outro lado, é comum o fato da cama de frango ser comercializada contendo cadáveres decompostos de aves ou mesmo não ter passado por qualquer processo de tratamento prévio, aumentando consideravelmente o risco de ocorrência do botulismo em bovinos. No presente estudo foi possível carac- terizar a alta letalidade da intoxicação botulínica, a ocorrência de sintomatologia e evolução clínica com quadro de paralisia progressiva de diferentes intensidades, culminando com a morte em períodos distintos ou a recuperação de animais, ausência de lesões macroscópicas primárias e detecção de esporos da bactéria na cama de frango utilizada. A presença de toxina botulínica tipos $\mathrm{C}$ ou $\mathrm{D}$ nas vísceras de animais que morreram com sintomatologia clínica, comprovou as evidências clínicopatológicas e epidemiológicas registradas nos surtos.

\section{REFERÊNCIAS}

Döbereiner J., Langenegger J., Tokarnia C.H. \& Dutra I.S. 1992. Epizootic botulism of cattle in Brazil. Dtsch. Tierärztl. Wochenschr. 99(5):188-190.

Dutra I.S. Epidemiologia, quadro clínico e diagnóstico, pela soroneutralização em camundongos, do botulismo em bovinos no Brasil, 19892002. Tese de Livre Docência, Curso de Medicina Veterinária, Unesp, Campus de Araçatuba. 133p.

Dutra I.S., Döbereiner J. 1996. Eficácia da Vaxall - vacina botulínica bivalente - na prevenção do botulismo em bovinos. Hora Veterinária, Porto Alegre, 93:22-26.

Dutra I.S, Döbereiner J., Rosa I.V., Souza L.A.A. \& Nonato M. 2001. Surtos de botulismo em bovinos associados à ingestão de água contaminada. Pesq. Vet. Bras. 21(2):43-48.

Hogg R.A., White V.J. \& Smith G.R. 1990. Suspected botulism in cattle associated with poultry litter. Vet. Rec. 126(19):476-479.

Kriek N.P.J. \& Odendaal M.W. 1994. Botulism, p.1354-1371. In: Coetzer J.A.W., Thomson G.R. \& Tustin R.C. (ed.) Infectious Diseases of Livestock. Oxford Press, Cape Town.

MAPA 2001. Instrução Normativa $\mathrm{n}^{\circ} \mathbf{1 5}$, de 17 de julho de 2001. Ministério da Agricultura, Pecuária e Abastecimento, Diário Oficial $n^{\circ}$ 138, Seção 1, de 18.7.2001.

McLoughlin M.F., Mcllroy \& Neil S.D. 1988. A major outbreak of botulism in cattle being fed ensiled poultry litter. Vet. Rec. 122(24):579-581.

Ribas A.I., Ferreira R.M.M., Masser R.C., Ciani R.B. \& Dutra I.S. 1994. Detecção de esporos de Clostridium botulinum em costelas de cadáveres decompostos de bovinos. Anais XXIII Congr. Bras. Med. Veterinária, Olinda, Pernambuco, p.142. (Resumo)

Smith L.D.S. 1977. Botulism: the organism, its toxins, the disease. Charles Thomas, Springfield. 236p.

Souza A.M. \& Langenegger J. 1987. Esporos de Clostridium botulinum em torno de cadáveres decompostos de bovinos em pastagens no sul de Goiás. Pesq. Vet. Bras. 7(1):17-22.

Stöber M. 1984. Differentialsymptomatologie einiger Krankheiten des zentralen Nervensystems des Rindes. Vet.-Med. Nachr. 2(1):99-121.

Theiler A. \& Robinson E.M. 1927. Der Botulismus der Haustiere. Ztschr. Infektionskr. 31:165-220.

Thrusfield M. 2004. Epidemiologia Veterinária. Editora Roca, São Paulo. $556 p$.

Tokarnia C.H., Langenegger J., Langenegger C.H. \& Carvalho E.V. 1970. Botulismo em bovinos no Estado do Piauí, Brasil. Pesq. Agropec. Bras., Sér. Vet., 5:465-472. 